\title{
The Study of Structural and Magnetic Properties of NiO Nanoparticles
}

\author{
Fardin Taghizadeh \\ Department of Physics, College of Sciences, Yasouj University, Yasouj, Iran \\ Email: taghizadeh@yu.ac.ir
}

Received 19 May 2016; accepted 22 August 2016; published 25 August 2016

\begin{abstract}
Nickel Oxide ( $\mathrm{NiO}$ ) is an important transition metal oxide with cubic lattice structure. Among the magnetic nanoparticles, fabrication of nickel nanoparticles is often more difficult than that of the other particles. This is because they are easily oxidized. To achieve pure nickel nanocrystals, numerous methods have been conducted in organic environments in order to prevent formation of hydroxide or oxidation. In the present work, we report the synthesis of NiO nanoparticles. Magnetic properties of $\mathrm{NiO}$ nanoparticles with different sizes and at different temperatures are compared. The phase structures, particle sizes and magnetic properties of $\mathrm{NiO}$ nanoparticles have been characterized by X-ray diffraction, TEM images and Vibrating Sample Magnetometer (VSM). We collected the experimental data reported in the literature, for the same conditions, and after fitting, extrapolating and doing some calculations. The magnetization for smaller nanoparticles is bigger for the samples we consider here. This difference could be explained by the difference of surface volume ratio of nanoparticle which shows the contribution of the paramagnetic surface is more important with respect to the anti-ferromagnetism of the core for smaller particles. Also the nanoparticle at lower temperatures shows bigger magnetization.
\end{abstract}

\section{Keywords}

Magnetization, Structural Properties, Nano Particles, Nickel Oxide

\section{Introduction}

As we know there is a fairly big difference between the physical properties of the bulk and nanoparticles, and also among nanoparticle themselves, for the same matter [1]. Here we concentrate on the magnetic properties of $\mathrm{NiO}$. It is anti-ferromagnetism up to 329 degree Kelvin and paramagnetic higher than this temperature [2] [3].

Magnetic nanoparticles are widely used in conductive colors [4] [5], chargeable batteries [6] [7], catalyzers [8], opto-electronics [9], magnetic recording devices [10], ferromagnetic fluids [11], magnetic resonance imaging with a high contrast, drug delivery, etc. [12].

Nickel is one of the transitional metals that has a magnetic property in relation with its bulk state and thus has interesting applications and properties such as hydrogen storage and catalytic properties. Using various methods such as electrochemical reduction [13], chemical reduction [14] [15], and cell-gel [16], one can prepare nickel nanoparticles. Recently, use of organic-metal precursors has gained a great deal of attention because it is possi- 
ble to control the size of particles, coordination level, crystallinity, and mono-dispersity of particles through it [17].

Among the magnetic nanoparticles, fabrication of nickel nanoparticles is often more difficult than that of the other particles. This is because they are easily oxidized. To achieve pure nickel nanocrystals, numerous methods have been conducted in organic environments in order to prevent formation of hydroxide or oxidation. Zhang et al. have prepared Ni nanocrystals with a diameter of 20 - $60 \mathrm{~nm}$ through degradation of nickel acetyl acetonate in oleyl amine [18].

Among the majority of advanced technologies for fabrication of nickel nanoparticles and nickel oxide, the thermal degradation is a new method for synthesis of mono-disperse and stable nanoparticles. In comparison with conventional methods, it is far quicker, cleaner, and more environmentally friendly, and through the thermal reduction process it should be optimized for fabrication of nickel nanoparticles with different sizes and shapes, since the shape and size for particles influence its application and properties.

\section{Fabrication Method}

In this method, metal nanoparticles and the metal oxide have been prepared through thermal degradation of the metal-surfactant complex in a hot surfactant solution. This method is schematically shown in Figure 1 demonstrating the fabrication of nickel oxide nanoparticles.

We produced $\mathrm{NiO}$ nanoparticles with particle diameters 25 - $100 \mathrm{~nm}$. We observed a phase transition at 38 and a coercively as high as $700 \mathrm{Oe}$ at $10 \mathrm{~K}$, although the bulk is anti-ferromagnetism.

Lopez and co-workers [19] prepared nanoparticles of $\mathrm{NiO}$ with a diameter size of $20-200 \mathrm{~nm}$. The magnetic properties of these nanoparticles show the presence of a net magnetic moment at the surface, due to the large surface volume ratio. Magnetization measurement of 150 Angstroms size NiO was reported by Makhlouf [20]. The structure and magnetics properties of NiO nanoparticles are investigated by Rai et al. [21] too. As mentioned above many researchers produced $\mathrm{NiO}$ nanoparticles and investigated their magnetic properties separately. Here we are interested to compare the magnetic behavior of the various size of $\mathrm{NiO}$ nanoparticles with each other and also with the bulk one [22]. Therefore we collected the experimental data from the articles mentioned in the References, although we could not find enough data with the same conditions. Then we fitted and extrapolated the data and did some calculations to plot the magnetization of the nanoparticles and compared them. We were aware of this point that when we compare the magnetic behavior of a sample containing nanoparticles with a different size, some difficulties will arise, e.g. the change in the density of a sample with changing the particle size, the change of the particle size with the temperature and the change of the structural properties inside the particles with their size. According to the variety of Physical and Chemical behaviors of 4 nanoparticles, and because the nanoparticles are small, it is better to study these systems, using computer simulation techniques.

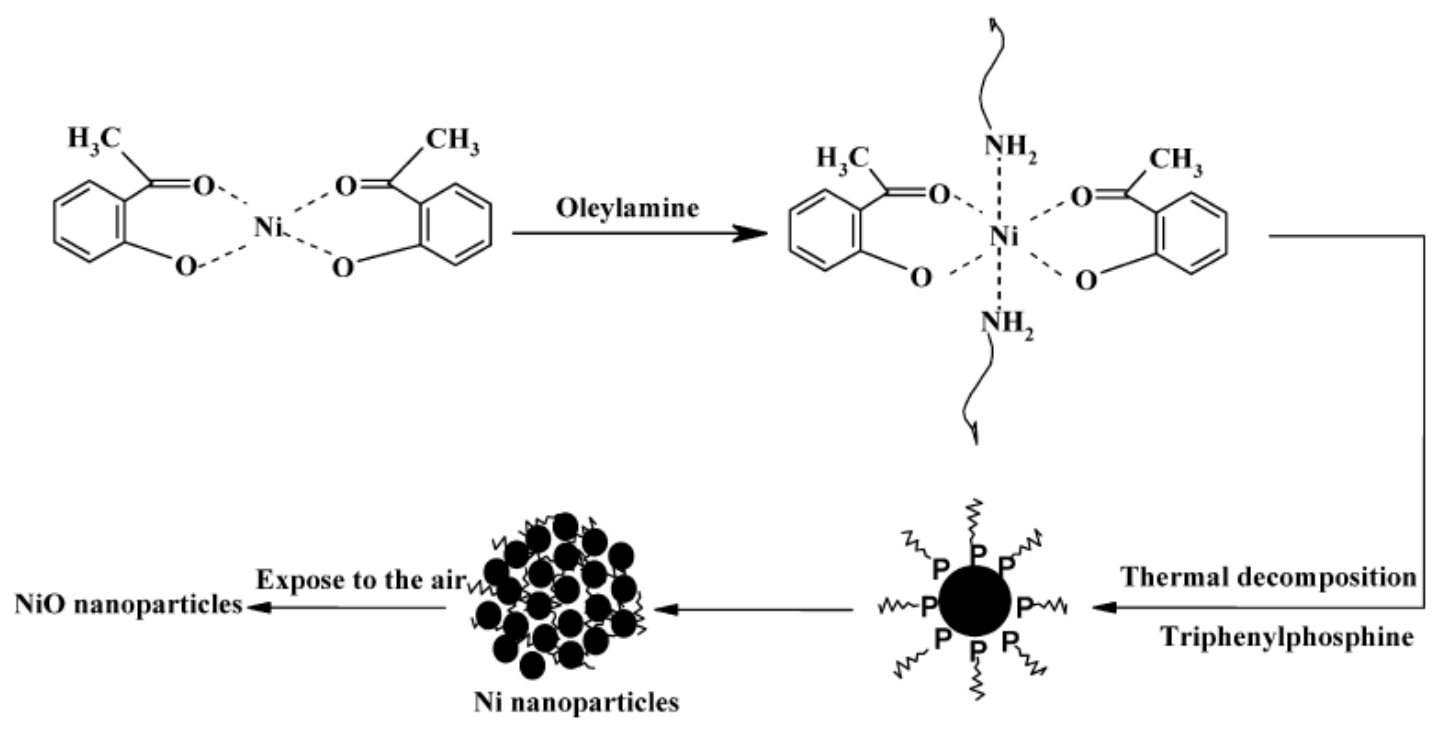

Figure 1. The procedure of fabrication of nickel oxide nanoparticles. 


\section{Result and Discussion}

\subsection{XRD Results}

The XRD pattern of nickel nanoparticles in Figure 2 demonstrates that the nickel nanoparticles have full facecentered cubic structure (fcc). Three peaks at $2 \theta, 45^{\circ}, 52.3^{\circ}$, and $77.4^{\circ}$ in nickel with a structure of fcc with planes of 111, 200, and 222 suggest the purity of nickel nanoparticles.

Nickel oxide nanoparticles were formed following the exposure of nickel nanoparticles to air after around 55 h. The XRD pattern of these particles is in the form of Figure 3. The image shows that nickel nanoparticles have transformed completely to nickel oxide nanoparticles with a high purity.

\subsection{TEM Results}

The images of Transmission Electron Microscopy (TEM) are shown in Figure 4(a). The size of nickel nanocrystals obtained by TEM has been 12 - $26 \mathrm{~nm}$, which is according to XRD data (Figure 4(a) and Figure 4(b)). These particles are pseudo-spherical. It is estimated that as the temperature increases to $250^{\circ} \mathrm{C}$, the majority of organic molecules are degraded. Therefore, only trace amounts of oleile amine molecules have been absorbed onto the surface of Ni nanoparticles. The ED pattern (Figure 4(b)) reveals that nickel nanoparticles are monocrystal. High-quality SEM images of nanoparticles show their high crystallinity. Light margins can be seen among the particles. The space between two adjacent particles is around $0.20 \mathrm{~nm}$. This space includes inter planar space at the nickel plane (200) with an fcc structure. The HRTEM image illustrates nickel nanoparticles, indicating high crystallinity of nickel nanoparticles (Figure 4(c)).

\subsection{Magnetic Results}

The magnetic properties of nickel nanoparticles are depicted in Figure 5. The saturated magnetization (Ms) is equal to $53.8 \mathrm{emug}^{-1}\left(1 \mathrm{emug}^{-1}=1 \mathrm{Am}^{2} \cdot \mathrm{kg}^{-1}\right)$, which is lower than the values of bulk nickel (55 Oe) (1 Oe = 79.6 $\mathrm{Am}^{-2}$ ). The bulk coercivity field $\left(\mathrm{H}_{\mathrm{c}}\right)$ of nickel particles is $0.8 \mathrm{Oe}$, which is around $49.2 \mathrm{Oe}$ for the nanoparticles. This increase is attributed to reduction in the size of nickel particles [23]. This point suggests that the magnetic properties of nickel nanoparticles are greater than those of nickel microstructures influenced by their size.

In Figure 6 and Figure 7 the magnetization is plotted against magnetic field for $10-40 \mathrm{~nm}$ and 50 - $100 \mathrm{~nm}$ for $\mathrm{T}=10 \mathrm{~K}$ and $\mathrm{T}=300 \mathrm{~K}$ respectively. As it is shown in the figures the relation between $\mathrm{M}$ and $\mathrm{H}$ (for $\mathrm{H}$ bigger than 0.5 Tesla) is almost linear. Therefore when the magnetic field is increasing, the relation between $\mathrm{M}$ and $\mathrm{H}$ is linear. The figures show that the amount of magnetization for $10-40 \mathrm{~nm}$ is bigger than $50-100 \mathrm{~nm}$ nanoparticles.

These differences could be explained by the difference surface volume ratio of nanoparticles which means the contribution of the paramagnetic or the effect of spines on the surface (it means: the spins increase as the particle size decreases) is more important with respect to the anti-ferromagnetism of the core for smaller particles.

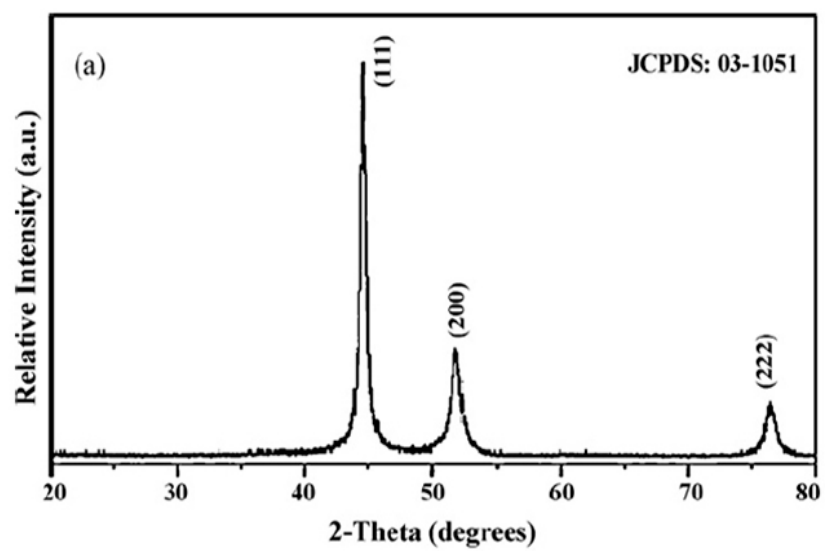

Figure 2. XRD pattern of Ni nanoparticles. 


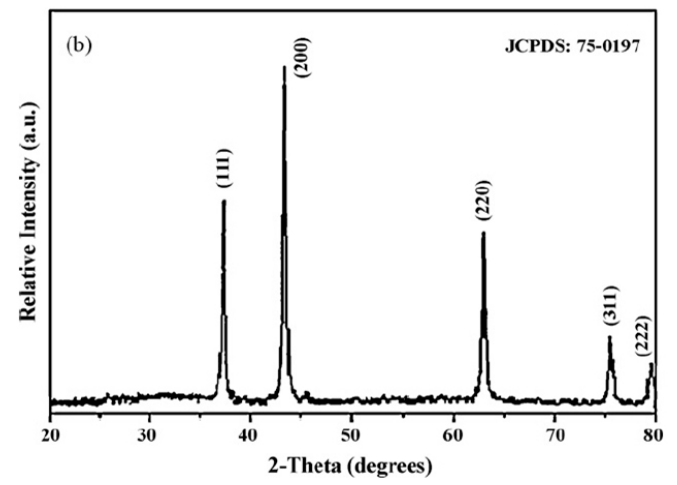

Figure 3. XRD pattern of Ni nanoparticles.
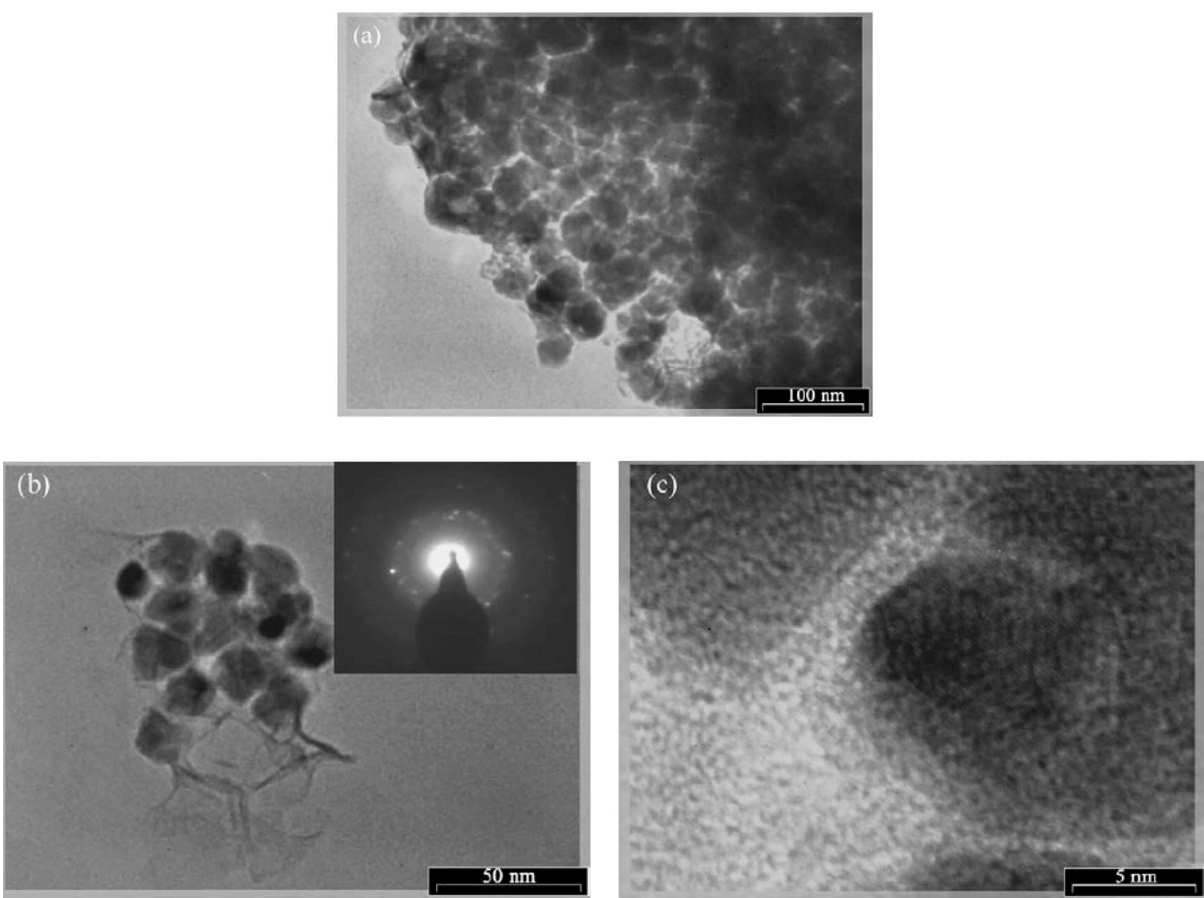

Figure 4. (a) and (b) TEM images of NiO nanoparticles and (c) HRTEM image of NiO nanoparticles.
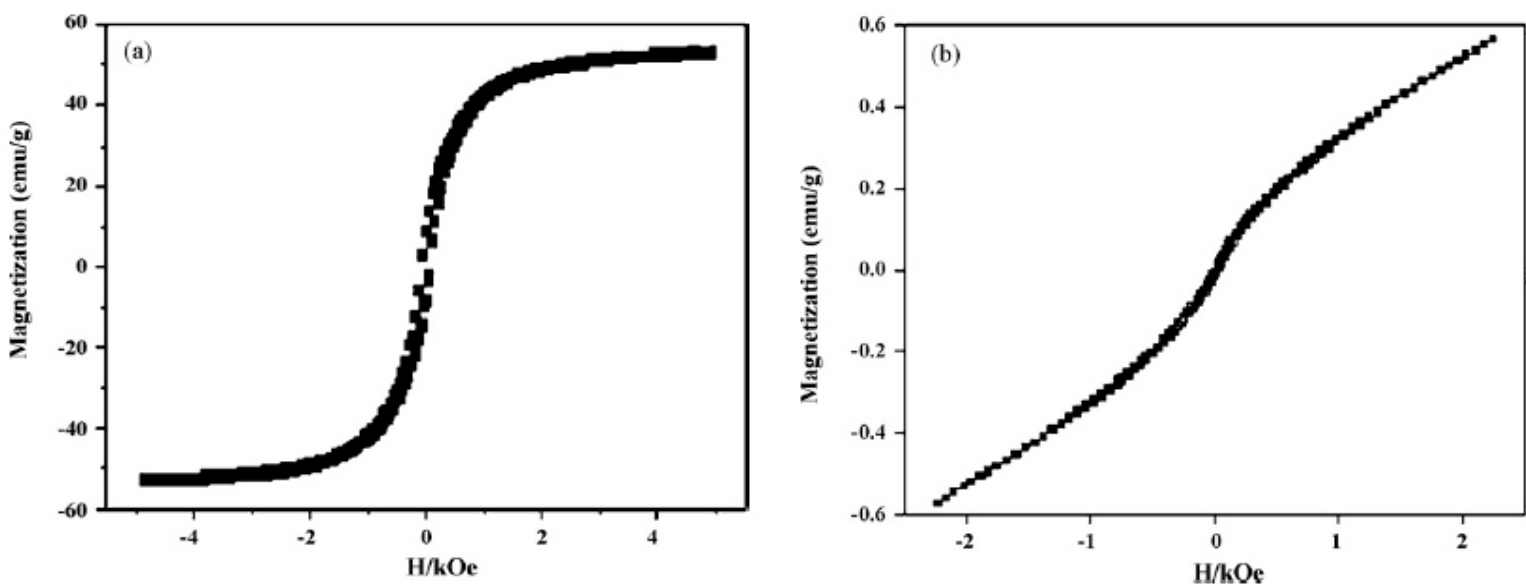

Figure 5. The magnetism curve of nanoparticles (a) Ni and (b) NiO at room temperature. 


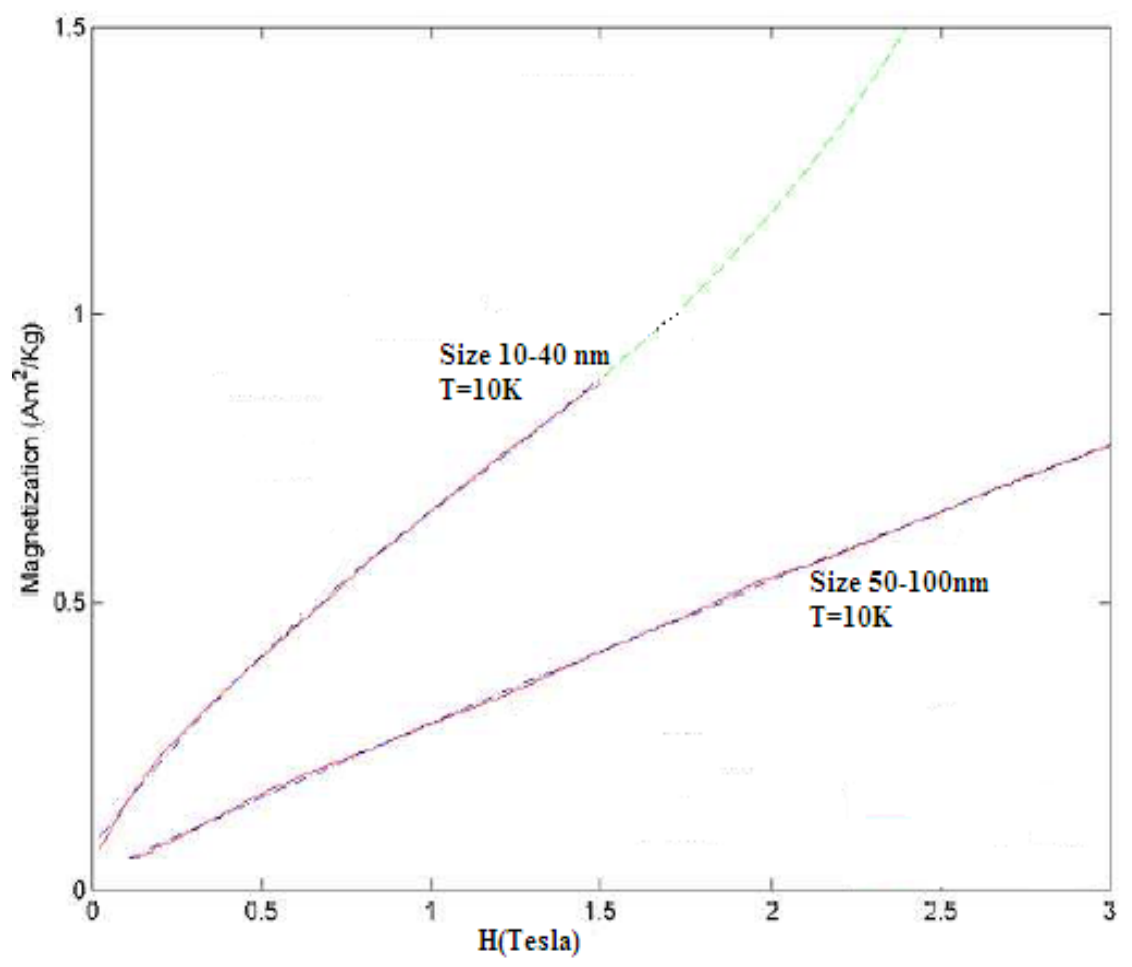

Figure 6. Magnetization of $\mathrm{NiO}$ nanoparticles for $10-40 \mathrm{~nm}$ and $50-100 \mathrm{~nm}$ at $\mathrm{T}=10 \mathrm{~K}$.

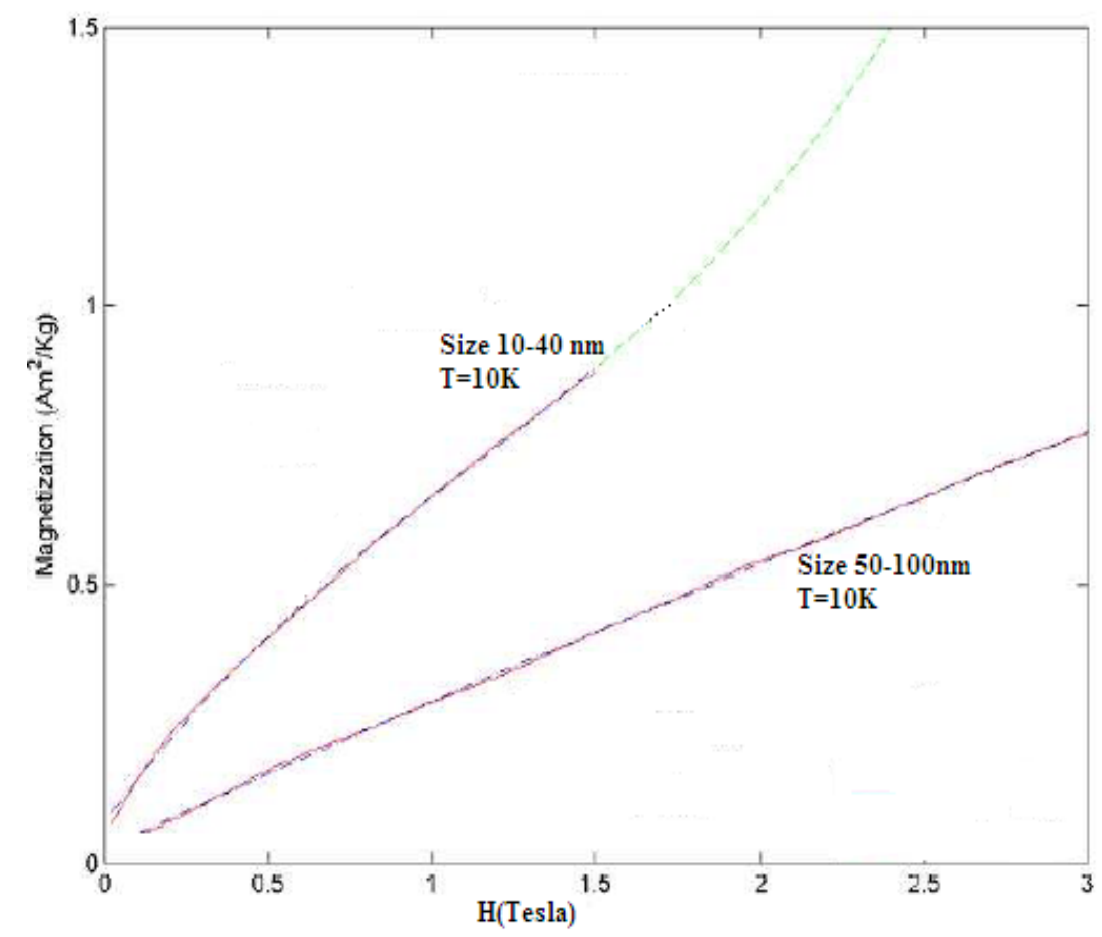

Figure 7. Magnetization of $\mathrm{NiO}$ nanoparticles for $10-40 \mathrm{~nm}$ and $50-100 \mathrm{~nm}$ at $\mathrm{T}=300 \mathrm{~K}$.

In Figure 6 and Figure 7 the magnetization is plotted and compared with two different temperatures. As is seen from the figures for given magnetic field, the magnetization at $10 \mathrm{~K}$ is bigger than $300 \mathrm{~K}$ which shows more ordering, particularly on the surface. 


\section{References}

[1] Wang, R. (2004) Nanoparticles: From Theory to Application. Colloid Polym Sci., 283, 466-466. http://dx.doi.org/10.1007/s00396-004-1234-9

[2] Wang, G., Lu, X., Zhai, T., Ling, Y., Wang, H., Tong, Y. and Li, Y. (2014) Sensitive Enzymatic Glucose Detection by TiO2 Nanowire Photoelectrochemical Biosensors Nanoscale. J. Mater. Chem. A, 4, 6153-6157.

[3] Han, D.Y., Yang, H.Y., Shen, C.B., Zhou, X. and Wang, F.H. (2004) Synthesis and Size Control of Nio Nanoparticles by Water-In-Oil Microemulsion. Powder Technology, 147, 113-116. http://dx.doi.org/10.1016/j.powtec.2004.09.024

[4] Liu, W.T. (2006) Nanoparticles and Their Biological and Environmental Applications. Journal of Biosience and Bioengineering, 102, 1-7. http://dx.doi.org/10.1263/jbb.102.1

[5] Aghazadeh, M., Golikand, A.N. and Ghaemi, M. (2011) Synthesis, Characterization, and Electrochemical Properties of Ultrafine B-Ni $(\mathrm{OH})_{2}$ Nanoparticles. International Journal of Hydrogen Energy, 36, 8674-8679. http://dx.doi.org/10.1016/j.ijhydene.2011.03.144

[6] Antolini, E., Ferretti, M. Gemme, M. S. (1996) Preparation of Porous Nickel Electrodes for Molten Carbonate Fuel Cells by Non-Aqueous Tape Casting. Journal of Materials Science, 31, 2187-2192. http://dx.doi.org/10.1007/BF00356644

[7] Gates, B.C. (1995) Supported Metal Clusters: Synthesis, Structure, and Catalysis. Chemical Reviews, 95, 511-522. http://dx.doi.org/10.1021/cr00035a003

[8] Lewis, L.N. (1993) Chemical Catalysis by Colloids and Clusters. Chemical Reviews, 93, 2693-2730. http://dx.doi.org/10.1021/cr00024a006

[9] Beecroft, L.L. and Ober, C.K. (1997) Nanocomposite Materials for Optical Applications. Chemistry of Materials, 9, 1302-1317. http://dx.doi.org/10.1021/cm960441a

[10] Hadjipanayis, G.C. (2012) Magnetic Hysteresis in Novel Magnetic Materials. Springer Science, Germany. https://books.google.com/books?isbn=9401154783

[11] Aharoni, A. (2000) Introduction to the Theory of Ferromagnetism. Oxford University Press, New York. https://books.google.com/books?isbn=0198508093

[12] Doria, G., Conde, J., Veigas, B., Giestas, L., Almeida, C., Assunção, M., Rosa, J. and Baptista, P.V. (2012) Noble Metal Nanoparticles for Biosensing Applications. Sensors, 12, 16577. http://dx.doi.org/10.3390/s120201657

[13] Hou, Y., Kondoh, H., Ohta, T. and Gao, S. (2005) Size-Controlled Synthesis of Nickel Nanopartzicles. Appl. Surf. Sci., 241, 218. http://dx.doi.org/10.1016/j.apsusc.2004.09.045

[14] Cordente, N., Amiens, C., Chaudret, B., Respaud, M., Senocq, F. and Casanove, M.J. (2003) Chemisorption on Nickel Nanoparticles of Various Shapes: Influence on Magnetism. J. Appl. Phys., 94, 6358. http://dx.doi.org/10.1063/1.1621081

[15] Davar, F., Zeinab, F. and Salavati-Neyasari, M. (2009) Nanoparticles Ni and Nio: Synthesis, Characterization and magnetic Properties. Journal of Alloys and Compounds, 476, 797-801. http://dx.doi.org/10.1016/j.jallcom.2008.09.121

[16] Gong, J., Wang, L.L., Liu, Y., Yang, J.H. and Zong, Z.J. (2008) Structural and Magnetic Properties of hcp and fcc Ni Nanoparticles. Journal of Alloys and Compounds, 457, 6-9. http://dx.doi.org/10.1016/j.jallcom.2007.02.124

[17] Murray, C.B., Sun, S., Doyle, H., Bettley, T. and Bull, M.R. (2001) Monodisperse 3d Transition-Metal (Co, Ni, Fe) Nanoparticles and Their Assembly into Nanoparticle Superlattices. MRS Bull., 26, 985-991. http://dx.doi.org/10.1557/mrs2001.254

[18] Zhang, H.T., Wu, G., Chen, X.H. and Qiu, X.G. (2006) Synthesis and Magnetic Properties of Nickel Nanocrystals. Materials Research Bulletin, 41, 495-501. http://dx.doi.org/10.1016/j.materresbull.2005.09.019

[19] Banobre-Lopez, M., Vazquez-Vazquez, C., Rivas, J. and Lopez-Quintela, M.A. (2003) Magnetic Properties of Chromium (III) Oxide Nanoparticles. Nanotechnology, 14, 318-322. http://dx.doi.org/10.1088/0957-4484/14/2/342

[20] Makhlouf, S.A. (2004) Magnetic Properties of $\mathrm{Cr}_{2} \mathrm{O}_{3}$ Nanoparticles. Journal of Magnetism and Magnetic Materials, 272-276, 1530-1532. http://dx.doi.org/10.1016/j.jmmm.2003.12.245

[21] Rai, A.K., Anh, L.T., Park, C.J., and Kimmical, J. (2013) Electrochemical Study of Nio Nanoparticles Electrode for Application in Rechargeable Lithium-Ion Batteries. Ceramics International, 39, 6611-6618. http://dx.doi.org/10.1016/j.ceramint.2013.01.097

[22] Duan, W.J., Lu, S.H. ,Wu, Z.L. and Wang, Y.S. (2012) Size Effects on Properties of NiO Nanoparticles Grown in Alkalisalts. J. Phys. Chem. C, 116 , 26043-26051. http://dx.doi.org/10.1021/jp308073c

[23] Hwang, J.H., Dravid, V.P., Teng, M.H., Host, J.J., Elliott, B.R. and Johnson, D.L. and Mason, T.O. (1997) Magnetic Properties of Graphitically Encapsulated Nickel Nanocrystals. Journal of Materials Research, 12, 1076-1082.

http://dx.doi.org/10.1557/JMR.1997.0150 


\section{Submit or recommend next manuscript to SCIRP and we will provide best service for you:}

Accepting pre-submission inquiries through Email, Facebook, LinkedIn, Twitter, etc.

A wide selection of journals (inclusive of 9 subjects, more than 200 journals)

Providing 24-hour high-quality service

User-friendly online submission system

Fair and swift peer-review system

Efficient typesetting and proofreading procedure

Display of the result of downloads and visits, as well as the number of cited articles

Maximum dissemination of your research work

Submit your manuscript at: http://papersubmission.scirp.org/ 